\title{
Preanalytical Procedures in the Measurement of Ionized Calcium in Serum and Plasma
}

\author{
Anders Kallner
}

Department of Clinical Chemistry, Karolinska Hospital, Stockholm, Sweden

\begin{abstract}
Summary: To investigate the effects of sampling routines, ionized calcium (corrected for $\mathrm{pH}$ ) was measured after sampling in different types of tubes and under fasting and postprandial conditions. The results are discussed with respect to analytical goals. Serum samples, collected in vacuum tubes and spun after coagulation, could be safely measured during $24 \mathrm{~h}$. This time window was expanded to 48 hours by using gel-containing tubes. Properly prepared specimens withstand mail transportation. Different brands of gel-containing tubes gave different results, and these differences were clinically significant. An "American-type" breakfast causes an average decrease of corrected ionized calcium ion concentration of $0.04 \mathrm{mmol} / \mathrm{l}$ and an increased interindividual variation of results. Characterisation of reference intervals should include the "nutritional status" and the brand of vacuum tube used.
\end{abstract}

\section{Introduction}

The concentration of calcium in plasma is accurately regulated in vivo. Only small variations within a narrow interval occur in healthy individuals (1). In blood, plasma and serum, calcium is essentially free ("ionized") or bound (various inorganic complexes are formed but calcium is also bound to proteins, particularly to albumin) as described in numerous reports (e.g. 1.c. ((2)). The equilibrium between the free and bound calcium depends on various factors, e.g. the metabolic status of the individual $(\mathrm{pH})$, the albumin concentration and hormone activities, particularly that of parathyrin and calcitonin. Under "normal" conditions the free calcium concentration is roughly half of the total S-Ca. However, "normal" conditions are not particularly relevant to the diagnosis and monitoring of hyper- or hypocalcaemia, so that simple algorithms to estimate the free fraction are not very useful in clinical practice.

The free fraction is routinely measured using ion-specific electrodes. The IFCC has had a working group dealing with theoretical and practical problems in this field for many years. The group has published a series of documents and recently a summary was published in the Journal of IFCC (2), based on the IFCC recommendations (3). The present study provides a basis for evaluating the risk of violating the recommendations.

Much attention has been paid to the preanalytical sources of errors (4-7). A major cause of variation is in vitro changes in $\mathrm{pH}$, because there is an inverse relationship between $\mathrm{pH}$ and ionized calcium concentration. There are mainly two biological reasons for changes of $\mathrm{pH}$ in plasma: loss of carbon dioxide due to the low partial pressure in ambient air, and lactate production by glycolysis. Loss of carbon dioxide affects the buffer system, causing an increase of the $\mathrm{pH}$ and subsequent decrease of the ionized calcium concentration. Glycolysis, on the other hand, reduces $\mathrm{pH}$. Polymers used in tubes and stoppers may absorb carbon dioxide to varying extents, and the effect is unknown of other additives, e. g. gels for separating serum and blood cells (8). Recommendations focus on anaerobic sampling and inhibition of glycolysis by separation of blood cells or use of inhibitors, e.g. fluoride.

Acute demands for immediate measurements of ionized calcium may not allow time for clotting and formation of serum. Acute measurements should therefore be made on blood or plasma drawn anaerobically using a suitable anticoagulant. Anticoagulants (citrate, EDTA, oxalate) act by complexing calcium and are therefore unsuitable. Also heparin complexes with free calcium. This can be minimized or overcome by use of small amounts of $\mathrm{Ca}$ heparinate ('Ca-titrated heparin' (2)) which has been successfully used as an anticoagulant (9).

In the non-acute situation it may be desirable to transport the sample or, for other reasons, to measure ionized calcium after some delay. The problem of storage has been addressed by IFCC $(3,4)$ but there is a need for recommended practical and sufficiently accurate procedures.

In the present report we address the practical aspects of preanalytical precautions for the measurement of ionized calcium.

\section{Materials and Methods}

An ICA 2 Ionized Calcium Analyzer (Radiometer, Copenhagen, Denmark) was used. The instrument measures $\mathrm{pH}$ and calcium ion 
concentration and makes an adjustment of the latter with respect to the actual $\mathrm{pH}$ (to $\mathrm{pH} 7.4$ ) according to a built-in algorithm in the interval pH 7.2-7.6. Vacuum tubes from Becton Dickinson (Vacutainer) and Terumo (Venoject) were used in the present study. Samples were drawn through the stopper of the vacuum tubes with a $1 \mathrm{ml}$ syringe and inmediately measured.

Participants were resting in a sitting, upright position for $15 \mathrm{~min}$ utes before sampling from an antecubital vein $(10)$. No or a minimum of stasis was applied. Except in the evaluation of the fasting state all samples were drawn between 08:00 and 09:00.

The precision of measurements was estimated by filling a syringe with fresh serum and making 11 consecutive readings within 25 minutes. Thus, ionized calcium was measured under maximally repeatable conditions. The coefficient of variation was $0.05 \%$, $0.40 \%$ and $0.32 \%$ for $\mathrm{pH}$, calcium ion concentration and the corrected calcium ion concentration, respectively. Factory control material was measured before and after each series of measurements. According to the protocol no measurements were made without recalibration and cleaning if the measured controls were outside or in the immediate vicinity of the recommended values. No drift in the results was observed for either component during the series of measurements and no calibration was necessary in addition to the built-in regular recalibration.

The participants in the first part of the present study were consecutive outpatients. Inclusion criteria were based on consent and absence of diagnosis related to calcium metabolism. In the second part, 24 healthy male and female volunteers participated.

\section{Part 1}

Four types of preanalytical procedures were investigated with respect to kind of tubes, additives and delays before measurement.

\section{Procedure 1: A}

Five individuals participated in this study. Plasma was collected in heparin tubes ( $2 \mathrm{ml}$ capacity) (dried heparin), serum was sampled in tubes ( $4 \mathrm{ml}$ capacity) containing gel, and blood in two tubes ( $4 \mathrm{ml}$ capacity) without addition. Measurements were made at 0 , 24, 48 and 72 hours. Thus, four tubes of each kind were filled, and about $56 \mathrm{ml}$ of blood was used from each participant. All tubes of each kind were filled at the same time and kept at ambient temperature $\left(20-22^{\circ} \mathrm{C}\right)$. The serum samples (gel tubes and empty tubes) were left to clot for 25 minutes and then spun ( $3000 \mathrm{~g}$ for $10 \mathrm{~min}$ ) and measured. The content of the second set of empty tubes was left to clot and contract, but not spun until measuring. The plasma tubes were spun immediately before measurements.

\section{Procedure 1: B}

Thirty individuals participated in the study of the performance of different brands of gel tubes: Vacutainer (Becton Dickinson) (15 individuals), and Venoject (Terumo) tubes (15 individuals).

\section{Procedure 1: C}

Two gel tubes Venoject (Terumo) were filled from each of fifteen patients. After clotting and centrifugation as above, one tube from each patient was measured as soon as possible, whereas the remaining tubes were mailed to an address outside the laboratory. The mail was delivered the following day and brought back to the laboratory by car and measured again the following morning. Thus, measurements were made after about 48 hours, and routine shipment.

\section{Procedure 1: D}

The effect of a brief exposure to ambient air was tested. Thus, samples were taken in gel tubes, allowed to clot and spun as above before measuring the ionized calcium concentration. Then, the stopper was removed for 10 minutes and replaced. The calcium ion concentration was again measured in the samples after about 5, 24 and 48 hours.

\section{Part 2}

Effects of fasting and food intake were studied in volunteers who had been fasting for 12 hours (overnight). Terumo gel tubes were used. The first sample was taken between 07:00 and 07:30, after which a standard breakfast (yoghurt, sausages, eggs, bread and butter and coffee) was served. Repeated sampling was performed between 09:00 and 09:30.

\section{Statistics}

Results were evaluated using Student's t-test ( $t_{\text {dep }}$ and $t_{\text {ind }}$ ), Wilcoxon test and ANOVA, when appropriate. A confidence level of $95 \%$ was used $(p<0.05)$. Sample multiple range analyses were made using "Statgraphics" version 6.0 (Manugistics, MD, US).

\section{Ethics committee}

Participants of the study gave their full informed consent and the study was approved by the Ethics Committee of the Karolinska Institute and Hospital.

\section{Results}

Gel-containing tubes from different suppliers (fig. 1) behave differently with respect to the time course of $\mathrm{pH}$ changes (note that in the figures, the values of corrected calcium activities have been increased by 0.5 and the $\mathrm{pH}$ reduced by 5.0 units to improve legibility and facilitate

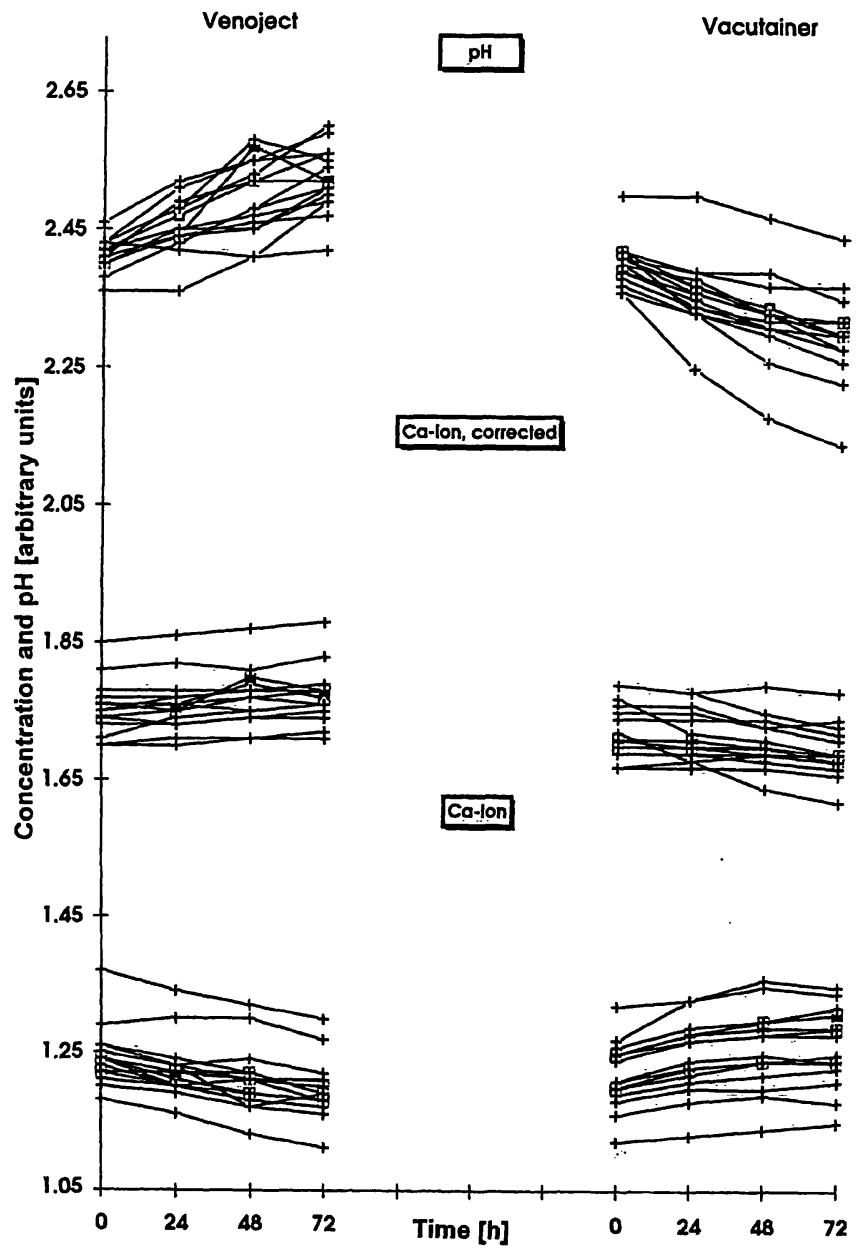

Fig. 1 Comparison between temporal changes of compounds in different brands of tubes.

Note that for the arbitrary units $\mathrm{pH}$ has been reduced by 5 units and the corrected $\mathrm{Ca}$ ion activities increased by $0.5 \mathrm{mmol} / \mathrm{l}$ to facilitate comparison of results. 
Tab. 1 Distribution data on measurements using different gel-containing tubes.

(Ambient temperature $20-22^{\circ} \mathrm{C}$.) Concentrations in $\mathrm{mmol} / \mathrm{l}$.

\begin{tabular}{|c|c|c|c|c|c|c|c|c|c|c|c|c|}
\hline & \multicolumn{4}{|l|}{$\mathrm{pH}$} & \multicolumn{4}{|c|}{ Calcium ion activity } & \multicolumn{4}{|c|}{ Corrected calcium ion activity } \\
\hline & $0 \mathrm{~h}$ & $24 \mathrm{~b}$ & $48 \mathrm{~h}$ & $72 \mathrm{~h}$ & $0 \mathrm{~h}$ & $24 \mathrm{~h}$ & $48 \mathrm{~h}$ & $72 \mathrm{~h}$ & $0 \mathrm{~h}$ & $24 \mathrm{~h}$ & $48 \mathrm{~h}$ & $72 \mathrm{~h}$ \\
\hline \multicolumn{13}{|l|}{ Venoject } \\
\hline $\begin{array}{l}\text { Mean } \\
N \\
\text { SD } \\
\text { SEM }\end{array}$ & $\begin{array}{c}7.411 \\
15 \\
0.025 \\
0.007\end{array}$ & $\begin{array}{c}7.454 \\
15 \\
0.040 \\
0.010\end{array}$ & $\begin{array}{c}7.495 \\
15 \\
0.055 \\
0.014\end{array}$ & $\begin{array}{c}7.522 \\
15 \\
0.047 \\
0.012\end{array}$ & $\begin{array}{l}1.244 \\
15 \\
0.044 \\
0.011\end{array}$ & $\begin{array}{l}1.225 \\
15 \\
0.044 \\
0.011\end{array}$ & $\begin{array}{l}1.211 \\
15 \\
0.048 \\
0.012\end{array}$ & $\begin{array}{c}1.195 \\
15 \\
0.044 \\
0.011\end{array}$ & $\begin{array}{c}1.253 \\
15 \\
0.040 \\
0.010\end{array}$ & $\begin{array}{c}1.259 \\
15 \\
0.040 \\
0.010\end{array}$ & $\begin{array}{c}1.270 \\
15 \\
0.041 \\
0.010\end{array}$ & $\begin{array}{c}1.273 \\
15 \\
0.041 \\
0.011\end{array}$ \\
\hline \multicolumn{13}{|c|}{ Vacutainer } \\
\hline $\begin{array}{l}\text { Mean } \\
N \\
\text { SD } \\
\text { SEM }\end{array}$ & $\begin{array}{c}7.403 \\
15 \\
0.034 \\
0.009\end{array}$ & $\begin{array}{c}7.359 \\
15 \\
0.052 \\
0.013\end{array}$ & $\begin{array}{c}7.325 \\
15 \\
0.062 \\
0.016\end{array}$ & $\begin{array}{c}7.298 \\
15 \\
0.066 \\
0.017\end{array}$ & $\begin{array}{l}1.221 \\
15 \\
0.049 \\
0.013\end{array}$ & $\begin{array}{l}1.246 \\
15 \\
0.055 \\
0.014\end{array}$ & $\begin{array}{l}1.259 \\
15 \\
0.059 \\
0.015\end{array}$ & $\begin{array}{l}1.261 \\
15 \\
0.057 \\
0.015\end{array}$ & $\begin{array}{l}1.224 \\
15 \\
0.040 \\
0.010\end{array}$ & $\begin{array}{l}1.217 \\
15 \\
0.037 \\
0.009\end{array}$ & $\begin{array}{l}1.207 \\
15 \\
0.037 \\
0.009\end{array}$ & $\begin{array}{l}1.195 \\
15 \\
0.038 \\
0.010\end{array}$ \\
\hline $\begin{array}{l}\text { t-ind } \\
\text { d. f. }\end{array}$ & $\begin{array}{l}0.734 \\
28\end{array}$ & $\begin{array}{l}5.608 \\
28\end{array}$ & $\begin{array}{l}7.944 \\
28\end{array}$ & $\begin{array}{l}10.707 \\
28\end{array}$ & $28^{1.353}$ & $\begin{array}{c}-1.155 \\
28\end{array}$ & $\begin{array}{c}-2.444 \\
28\end{array}$ & $\begin{array}{c}-3.55 \\
28\end{array}$ & $28^{1.985}$ & $\begin{array}{l}2.985 \\
28\end{array}$ & $\begin{array}{l}4.418 \\
28\end{array}$ & $\begin{array}{l}5.404 \\
28\end{array}$ \\
\hline
\end{tabular}

comparison between results of the graph). Consequently, the calcium ion concentration changes but is partly corrected by the normalization algorithm. A significant difference (Student's $t_{\text {ind }}$ ) between the sets of tubes develops in the second measurement of corrected calcium concentration, i. e. after 24 hours. As detailed in table 1 , the difference between the group means is about 0.04 $\mathrm{mmol} / \mathrm{l}$ in the corrected calcium ion concentration after $24 \mathrm{~h}$. A significant difference in uncorrected results develops after $48 \mathrm{~h}$.

The time courses of change of $\mathrm{pH}$, ionized calcium and corrected ionized calcium in the different types of tubes are summarized in figure 2 . The drop in $\mathrm{pH}$ is similar in the heparinized blood and the unspun and undecanted samples, whereas the changes are less dramatic in the centrifuged but undecanted sample.

As detailed in table 2, ionized calcium measured in serum gave largely the same results when measured in tubes with or without gel at time 0 , i. e. about 30 minutes after sampling. The same samples measured in heparin plasma gave lower results $(p<0.05)$. When measured after 24 and 48 hours, the corrected ionized calcium concentration had decreased significantly (ANOVA) in all types of tubes except those with gel and those that were centrifuged. The average decrease of "corrected" calcium ion concentration in the "empty" tubes was about $0.01 \mathrm{mmol} / 1$ after $24 \mathrm{~h}$. After 72 hours calcium ion activities in gel tubes were also statistically changed although the mean difference was less than $0.01 \mathrm{mmol} / \mathrm{l}$.

The uncorrected serum ionized calcium concentration was changed in all tubes as early as 24 hours after sampling.

Differences between measurements made after mailing and those made immediately varied according to the tested brands of gel tubes (tab. 3). Significance of changes were tested using Student's $t_{d e p}$. The magnitude and direction of the changes are in accordance with those recorded in samples which had been stored in the laboratory for an equal length of time. No macroscopic haemolyses were observed in the tubes.

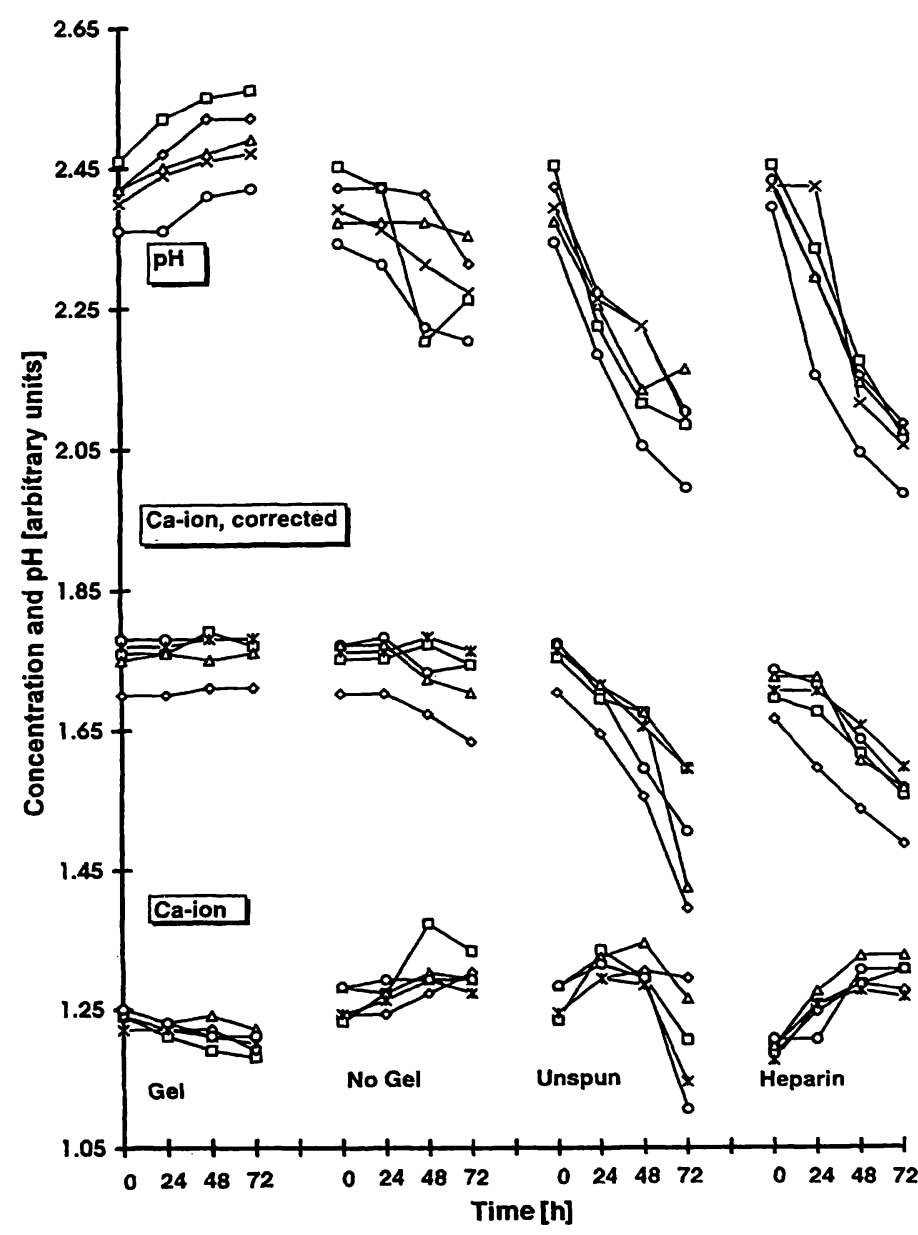

Fig. 2 Temporal changes in $\mathrm{pH}$, corrected $\mathrm{Ca}$ ion concentration, and $\mathrm{Ca}$ ion concentration (from top to bottom) in different topes of tubes.

Note that for the arbitrary units pH has been reduced by 5 units and the corrected $\mathrm{Ca}$ ion activities increased by $0.5 \mathrm{mmol} / \mathrm{l}$ to facilitate comparison of results. 
Tab. 2 Temporal changes in concentrations in samples from live different persons collected in different types of tubes (ambient temperature $20-22^{\circ} \mathrm{C}$ ). Concentrations in $\mathrm{mmol} / \mathrm{l}$.

\begin{tabular}{|c|c|c|c|c|c|c|c|c|c|c|c|c|c|c|c|c|}
\hline & \multirow[t]{2}{*}{ Time } & \multicolumn{3}{|l|}{$\# 1$} & \multicolumn{3}{|l|}{$\# 2$} & \multicolumn{3}{|l|}{ \#3 } & \multicolumn{3}{|l|}{$\# 4$} & \multicolumn{3}{|l|}{ \#5 } \\
\hline & & $\mathrm{pH}$ & $\mathrm{Ca}$ & $\begin{array}{l}\text { Corr } \\
\mathrm{Ca}\end{array}$ & $\mathrm{pH}$ & $\mathrm{Ca}$ & $\begin{array}{l}\text { Corr } \\
\mathrm{Ca}\end{array}$ & $\mathrm{pH}$ & $\mathrm{Ca}$ & $\begin{array}{l}\text { Corr } \\
\mathrm{Ca}\end{array}$ & $\mathrm{pH}$ & $\mathrm{Ca}$ & $\begin{array}{l}\text { Corr } \\
\mathrm{Ca}_{1}\end{array}$ & $\mathrm{pH}$ & $\mathrm{Ca}$ & $\begin{array}{l}\text { Corr } \\
\mathrm{Ca}\end{array}$ \\
\hline Gel, spun & $\mathrm{Oh}$ & 7.46 & 1.24 & 1.28 & 7.42 & 1.24 & 1.26 & 7.42 & 1.25 & 1.27 & 7.36 & 1.22 & 1.20 & 7.40 & 1.25 & 1.25 \\
\hline Gel, spun & $24 \mathrm{~h}$ & 7.52 & 1.21 & 1.28 & 7.47 & 1.22 & 1.26 & 7.45 & 1.23 & 1.27 & 7.36 & 1.22 & 1.20 & 7.44 & 1.23 & 1.26 \\
\hline Gel, spun & $48 \mathrm{~h}$ & 7.55 & 1.19 & 1.28 & 7.52 & 1.22 & 1.29 & 7.47 & 1.24 & 1.28 & 7.41 & 1.21 & 1.21 & 7.46 & 1.21 & 1.25 \\
\hline Gel. spun & $72 \mathrm{~h}$ & 7.56 & 1.18 & 1.28 & 7.52 & 1.19 & 1.27 & 7.49 & 1.22 & 1.28 & 7.42 & 1.20 & 1.21 & 7.47 & 1.21 & 1.26 \\
\hline No gel, spun & $0 \mathrm{~h}$ & 7.45 & 1.23 & 1.27 & 7.42 & 1.24 & 1.25 & 7.37 & 1.28 & 1.26 & 7.34 & 1.24 & 1.20 & 7.39 & 1.28 & 1.27 \\
\hline No gel, spun & $24 \mathrm{~h}$ & 7.42 & 1.27 & 1.28 & 7.42 & 1.24 & 1.25 & 7.37 & 1.27 & 1.26 & 7.31 & 1.26 & 1.20 & 7.36 & 1.29 & 1.27 \\
\hline No gel, spun & $48 \mathrm{~h}$ & 7.20 & 1.37 & 1.23 & 7.41 & 1.27 & 1.27 & 7.37 & 1.30 & 1.28 & 7.22 & 1.29 & 1.17 & 7.31 & 1.29 & 1.22 \\
\hline No gel, spun & $72 \mathrm{~h}$ & 7.26 & 1.33 & 1.24 & 7.31 & 1.30 & 1.24 & 7.35 & 1.29 & 1.26 & 7.2 & 1.27 & 1.13 & 7.27 & 1.29 & 1.20 \\
\hline No gel. unspun & $\mathrm{Oh}$ & \multicolumn{15}{|c|}{ see above } \\
\hline No gel, unspun & $24 \mathrm{~h}$ & 7.22 & 1.33 & 1.20 & 7.27 & 1.29 & 1.19 & 7.25 & 1.32 & 1.21 & 7.18 & 1.29 & 1.14 & 7.26 & 1.31 & 1.21 \\
\hline No gel, unspun & $48 \mathrm{~h}$ & 7.11 & 1.29 & 1.09 & 7.22 & 1.30 & 1.17 & 7.13 & 1.34 & 1.15 & 7.05 & 1.28 & 1.05 & 7.22 & 1.29 & 1.17 \\
\hline No gel, unspun & $72 \mathrm{~h}$ & 7,08 & 1.20 & 1.00 & 7.10 & 1.29 & 1.09 & 7.16 & 1.26 & 1.09 & 6.99 & 1.14 & 0.89 & 7.09 & 1.10 & 0.92 \\
\hline Heparinized & $\mathrm{Oh}$ & 7.45 & 1.19 & 1.23 & 7.43 & 1.18 & 1.19 & 7.42 & 1.19 & 1.20 & 7.39 & 1.17 & 1.16 & 7.42 & 1.20 & 1.22 \\
\hline Heparinized & $24 \mathrm{~h}$ & 7.33 & 1.25 & 1.21 & 7.29 & 1.24 & 1.17 & 7.29 & 1.27 & 1.20 & 7.15 & 1.25 & 1.09 & 7.42 & 1.20 & 1.22 \\
\hline Heparinized & $48 \mathrm{~h}$ & 7.17 & 1.28 & 1.13 & 7.15 & 1.28 & 1.11 & 7.14 & 1.32 & 1.15 & 7.04 & 1.27 & 1.03 & 7.11 & 1.30 & 1.10 \\
\hline Heparinized & $72 \mathrm{~h}$ & 7.06 & 1.30 & 1.06 & 7.08 & 1.27 & 1.05 & 7.07 & 1.32 & 1.09 & 6.98 & 1.26 & 0.98 & 7.05 & 1.30 & 1.06 \\
\hline
\end{tabular}

As early as about 5 hours after removing the stopper for 10 minutes and then replacing it, there was a significant increase in the $\mathrm{pH}$ and a decrease of the ionized calcium concentration. This study was only carried out with the Venoject tubes. There was no statistically significant change in the concentration of the corrected ionized calcium. After 24 hours the average increase of corrected ionized calcium concentration in the studied group was $0.03 \pm 0.015 \mathrm{mmol} / \mathrm{l}$. After an additional 24 hours the corresponding increase was $0.06 \pm 0.02$ $\mathrm{mmol} / \mathrm{l}$.

The individual responses to food are illustrated in figure 3 and the results summarized in table 4 . Increases in $\mathrm{pH}$ and decreases in calcium ion activities are statistically significant (Student's $t_{\text {dep }} p<0.05$ ), as is the increase of the variance of the distribution (tab. 4).

\section{Discussion}

The following hypotheses were tested:

1. Spun serum using gel tubes and without decanting can be used.

Tab. 3 Changes (and SD) observed after mailing ( $-=$ decrease). Concentrations in $\mathrm{mmol} / \mathrm{l} . \mathrm{N}=15$.

\begin{tabular}{lll}
\hline & Venoject & Vacutainer \\
\hline $\mathrm{pH}$ & $0.05(0.053)$ & $-0.10(0.050)$ \\
& $\mathrm{p}<0.05$ & $\mathrm{p}<0.05$ \\
Calcium ion & $-0.02(0.016)$ & $0.05(0.015)$ \\
& n.s. & $\mathrm{p}<0.05$ \\
Calcium ion, corr & $0.02(0.019)$ & $-0.03(0.028)$ \\
& $\mathrm{p}<0.05$ & $\mathrm{p}<0.05$ \\
\hline
\end{tabular}

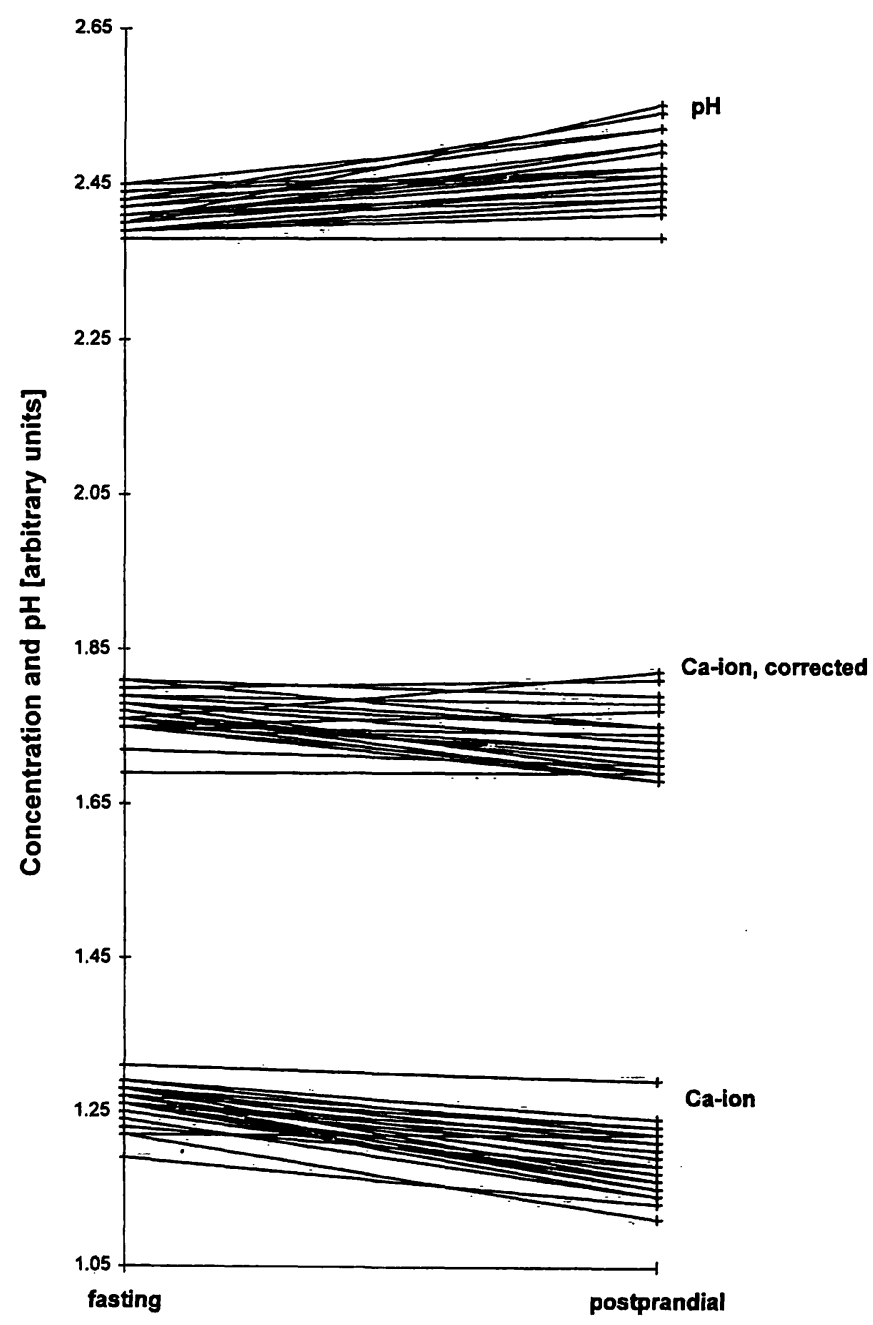

Fig. 3 Effect of an "American-type" breakfast on the measured analytes.

Note that for the arbitrary units $\mathrm{pH}$ has been reduced by 5 units and the corrected $\mathrm{Ca}$ ion activities increased by $0.5 \mathrm{mmol} / \mathrm{l}$ to facilitate comparison of results. 
Tab. 4 Postpranidal changes. Concentrations in mmol/l. $\mathrm{N}=24$.

\begin{tabular}{|c|c|c|c|c|c|c|}
\hline & \multicolumn{2}{|l|}{$\mathrm{pH}$} & \multicolumn{2}{|l|}{ Ca-ion } & \multicolumn{2}{|c|}{ Ca-ion, corr } \\
\hline & fasting & $\begin{array}{l}\text { post- } \\
\text { pran- } \\
\text { dial }\end{array}$ & fasting & $\begin{array}{l}\text { post- } \\
\text { pran- } \\
\text { dial }\end{array}$ & fasting & $\begin{array}{l}\text { post- } \\
\text { pran- } \\
\text { dial }\end{array}$ \\
\hline $\begin{array}{l}\text { Mean } \\
\text { SD }\end{array}$ & $\begin{array}{l}7.41 \\
0.02\end{array}$ & $\begin{array}{l}7.47 \\
0.04\end{array}$ & $\begin{array}{l}1.26 \\
0.03\end{array}$ & $\begin{array}{l}1.19 \\
0.04\end{array}$ & $\begin{array}{l}1.27 \\
0.03\end{array}$ & $\begin{array}{l}1.23 \\
0.04\end{array}$ \\
\hline
\end{tabular}

2. Gel tubes from different vendors can be used.

3. Commercial heparin tubes can be used.

4. Spun serum without decanting can be used.

5. Unspun tubes without coagulant can be used.

6. 1., 2., 3. and 4. can be saved for up to three days at ambient temperature, $20-22^{\circ} \mathrm{C}$.

7. 1. can be mailed under ambient conditions (temperature $10-22^{\circ} \mathrm{C}$, no air mail).

8. Removal of the stopper jeopardizes measurements of ionized calcium.

9. 'American-style breakfast' does not influence the results.

The importance of the posture of the patient for proteins and protein bound components has been described (10). In this study conditions were standardized by requiring that the participant rested in a sitting position for 15 minutes before sampling.

The results confirm that ionized calcium activities differ if measured in serum or heparin plasma. The tubes used contained sodium heparinate and it is known that heparin should be saturated by titration with calcium to avoid the binding $(5,6)$ of calcium. The continued decrease of $\mathrm{pH}$ suggests production of lactic acid in the tubes which contained plasma or serum exposed to blood corpuscles. As expected, a concomitant increase of the measured ionized calcium ion concentration was registered. The latter was largely corrected within the acceptable range for corrections given in the literature (2) and instrument manual (pH 7.2-7.6), but the lower limit of this range was exceeded by $2 \mathrm{~h}$ after sampling. Initially activities were lower in heparin plasma than in serum, presumably due to the use of sodium rather than calcium heparinate. Ordinary heparin containing vacuum tubes are therefore not suitable. It may always be argued, though, that serum is never present in vivo and thus its composition may not be truly representative for the patient. However, Ca-heparinate-containing vacuum tubes are not commonly available, and their use would add to the complexity of the logistics of everyday practice.

The changes in iononized calcium concentration are inversely related to the changes in $\mathrm{pH}(11)$, and the correction algorithm (2) manages to correct the changes to a considerable degree. In the present study design, decreases in $\mathrm{pH}$ were of such a magnitude that the lower limit of the acceptable range was exceeded and the correction then failed (fig. 2). The only increased $\mathrm{pH}$ noted (Venoject tube with gel after $72 \mathrm{~h}$ ) did not exceed 7.6.

The postprandial "alkaline tide" is known to increase $\mathrm{pH}$ and reduce the ionized calcium concentration $(12,13)$. The standardized breakfast indeed caused the expected changes as measured after two hours. Since the shift in calcium concentration (both directly measured and after correction) occurs after the alkaline tide has virtually ceased, other postprandial mechanisms may also influence the calcium concentration.

\section{Conclusions}

If ionized calcium can be measured immediately after coagulation and centrifugation, there is no difference between untreated tubes and those containing a corpuscleseparating gel. The latter tubes can be saved for 48 hours without a significant change in the ionized calcium ion concentration corrected for changes in $\mathrm{pH}$. If there is no gel, measurements should be made within 24 hours provided the tubes are spun but not decanted. After 72 hours the difference from the initially measured concentration becomes statistically significant, even in gel tubes, although the mean difference is small. Interestingly, there is a marked difference between tubes from two major suppliers, indicating that the gel indeed interferes with the determination. There is no significant initial difference, but since the trends are opposite, the difference becomes significant for the corrected calcium ion concentration and $\mathrm{pH}$ as early as 24 hours after sampling.

Properly centrifuged gel-containing tubes withstand mailing without significantly larger changes of measured calcium activities than those stored the same time in the laboratory. The difference in comparison with the initially measured concentration is however statistically significant. Again, the different makes of gel tubes showed diverging results, but the difference was not corrected by the algorithm of the instrument, although the changes in $\mathrm{pH}$ were within the dynamic range.

Food intake affects the results of measurements of ionized calcium. The changes were statistically significant indicating a decrease in calcium ion concentration, and it is noteworthy that the interindividual distribution of results increased.

\section{Analytical goals}

The question arises of whether differences recorded in the study, even if statistically significant, have any clinical implications. Analytical goals should preferentially 
be set in relation to biological variances (e. g. lc. (1)). It is generally accepted that the variation of serum calcium concentration is small, amounting to a coefficient of variation of about $2.0 \%$ to $2.6 \%$ (intra-individual) and $1.5 \%$ (inter-individual) in healthy man (1). The suggestions by Cotlove and Harris and the recommendations of the 1976 College of American Pathologists (1) indicate that for calcium, the analytical goal (coefficient of variation) should be $0.9 \%$. In the absence of literature data on inter- and intra-individual variations of ionized calcium, the same goal is suggested. The precision of the present measurement procedure amounts to about $0.4 \%$ which would allow for further $0.8 \%$ variation before reaching the limit of the analytical goal. If this is acceptable, a difference of about $0.01 \mathrm{mmol} / 1$ would be acceptable without further correction.

If the difference were accepted the present study suggests the following recommendation: Results of mea-

\section{References}

1. Fraser CG. The application of theoretical goals based on biological variation data in proficiency testing. Arch Pathol Lab Med 1988; 112:404-15.

2. Boink ABTJ, Buckley BM, Christiansen TF, Covington AK, Maas AHJ, Müller-Plathe O, et al. Recommendation on sampling, transport, and storage for the determination of the concentration of ionized calcium in whole blood, plasma and serum. JIFCC 1992; 4:147-52.

3. Boink ABTJ, Buckley BM, Christiansen TF, Covington AK, Maas AHJ, Müller-Plathe O, et al. IFCC recommendations on sampling, transport and storage for the determination of the concentration of ionized calcium in whole blood, plasma and serum. Eur J Clin Chem Blin Biochem 1991; 29:767-72.

4. Thode J, Fogh-Andersen N, Aas F, Siggard-Andersen O. Sampling and storage of blood for determination of ionized calcium. Scand J Clin Lab Invest 1985; 45:131-8.

5. Feistel CC, Boehm G, Kuo C. Effects of sample handling procedure on free ionized calcium concentration in whole blood and serum. In: Maas, AHJ, Kofstad J, Siggard-Andersen $\mathrm{O}$, Kokholm G, editors. Ionized calcium, sodium, and potassium by ion selective electrodes. IFCC Workshop, Oslo 1983; 5:111-22.

6. Graham GA, Johnson LA. The stability of serum ionized calcium during sample-handling and analysis. In: Maas, AHJ, Buckley B, Manzoni A, Moran RF, Siggaard-Anderson O., editors. Methodology and clinical applications of ion-selective electrodes. Private Press: Sprokholt R 1988; 10:55. surements in spun serum samples are acceptable up to about $24 \mathrm{~h}$ after sampling. Gel-containing tubes give acceptable results up to about $48 \mathrm{~h}$ after sampling. Stoppers may be removed for a short time, but then the calcium concentration must be measured within about $5 \mathrm{~h}$. Mailing of samples is just about possible. The "nutritional state" should be defined. Due to the increased inter-individual variation, sampling during fasting is recommended. The systematic difference between different brands of tubes makes it important to specify which reference interval applies to a particular brand of tube. This becomes particularly important if measurements are made after an extended delay $(<24 \mathrm{~h})$.

\section{Acknowledgements}

This study was supported by Karolinska Institutes' Fonder.

7. Radde IC, Höffken B, Parkinson DK, Sheepers J, Luckham A Practical aspects on a measurement for calcium ion activity in plasma. Clin Chem 1971; 17:1002-6.

8. Larsson L, Öhman S. Effect of silicone-separator tubes and storage time on ionized calcium in serum. Clin Chem 1985; 168:168-9.

9. Törring $\mathrm{O}$, Sjöberg $\mathrm{HE}$. A calcium clamp technique in man. Acta Physiol Scand 1983; 119:387-92.

10. Felding P, Tryding N, Hyltoft-Petersen P, Hørder M. Effects of posture on concentrations of blood constituents in healthy adults. Practical application of blood specimen collection procedures recommended by the Scandinavian Committee on Reference Values. Scand J Clin Lab Invest 1980; 40:615-21.

11. Thode J, Fogh-Andersen N, Wimberley PD, Müller-Sörensen $A$, Siggaard-Andersen $O$. Relation between $\mathrm{pH}$ and ionized calcium in vitro and in vivo in man. Scan J Clin Lab Invest 1983; 165 Suppl 43:79-82.

12. Young DS, Bermes EW. In: Burtis CA, Ashwood ER, editors. Tietz Textbook of clinical chemistry. Burtis CA, New York: Saunders, 1994.

13. Searmonds B, Towfighi J, Arvan DA. Determination of ionized calcium in serum by use of an ion selective electrode. Clin Chem 1972; 18:155-60.

\section{Received August 9/September 28, 1995}

Corresponding author: Dr. A. Kallner, Avd. klinisk kemi, Karolinska sjukhuset, S-171 76 Stockholm, Sweden 